\title{
Staphylococcus epidermidis and Staphylococcus haemolyticus: detection of biofilm genes and biofilm formation in blood culture isolates from patients in a Brazilian teaching hospital
}

\author{
Luiza Pinheiro a,b,*, Carla Ivo Brito ${ }^{\mathrm{a}, \dagger}$, Adilson de Oliveira ${ }^{\mathrm{a}}$, \\ Valéria Cataneli Pereira ${ }^{a}$, Maria de Lourdes Ribeiro de Souza da Cunha ${ }^{\mathrm{a}, 1}$ \\ a Departamento de Microbiologia e Imunologia, Instituto de Biociências, Universidade Estadual Paulista, UNESP, Botucatu, SP, Brazil \\ b Laboratório de Patologia,Instituto Lauro de Souza Lima, Bauru, SP, Brazil
}

\section{A R T I C L E I N F O}

\section{Article history:}

Received 24 February 2016

Received in revised form 17 May 2016

Accepted 4 June 2016

Available online 7 June 2016

\section{Keywords:}

Biofilm

Staphylococcus epidermidis

Staphylococcus haemolyticus

ica genes

bhp

\begin{abstract}
A B S T R A C T
Infections with coagulase-negative staphylococci are often related to biofilm formation. This study aimed to detect biofilm formation and biofilm-associated genes in blood culture isolates of Staphylococcus epidermidis and S. haemolyticus. Half (50.6\%) of the 85 S. epidermidis isolates carried the icaAD genes and $15.3 \%$ the bhp gene, while these numbers were $42.9 \%$ and 0 for $S$. haemolyticus, respectively. According to the plate test, 30 S. epidermidis isolates were biofilm producers and $40 \%$ of them were strongly adherent, while only one (6\%) of the $17 \mathrm{~S}$. haemolyticus biofilm-producing isolates exhibited a strongly adherent biofilm. The concomitant presence of $i c a A$ and $i c a D$ was significantly associated with the plate and tube test results $(P \leq 0.0004)$. The higher frequency of $i c a A$ in $S$. epidermidis and of $i c a D$ in $S$. haemolyticus is correlated with the higher biofilm-producing capacity of the former since, in contrast to IcaD, IcaA activity is sufficient to produce small amounts of polysaccharide. Although this study emphasizes the importance of $i c a A D$ and $b h p$ for biofilm formation in S. epidermidis, other mechanisms seem to be involved in S. haemolyticus.
\end{abstract}

(c) 2016 Elsevier Inc. All rights reserved.

\section{Background}

Coagulase-negative staphylococci (CoNS), particularly Staphylococcus epidermidis and Staphylococcus haemolyticus, are considered important nosocomial agents of medical device-associated infections (Vuong and Otto, 2002). Biofilm production is one of the main factors involved in the pathogenesis of these infections (Huebner and Goldmann, 1999). The biofilm permits the adherence and persistence of bacteria in foreign materials. Furthermore, bacteria organized in biofilms are protected from antimicrobials and from the host immune system (Mack et al., 2007).

The steps of biofilm production in S. epidermidis include adherence, in which adhesive proteins such as autolysin and adhesin (AtlE and Aae), Fbe/Sdrg, Embp, and lipase GehD play important roles (Mack et al., 2007). Polysaccharide intercellular adhesin (PIA), encoded by the icaADBC locus, is the main component of the accumulation step(Mack et al., 2007).The glycosyltransferase activity of PIA is increased when

\footnotetext{
* Corresponding author. Tel.: +55-143-8800-428

E-mail addresses: luizapinheiro@ibb.unesp.br, luhh_pinheiro@hotmail.com (L. Pinheiro), adilson270193@gmail.com (A. Oliveira), cataneli@ibb.unesp.br (V.C. Pereira), cunhamlr@ibb.unesp.br (M.L.R.S. Cunha).

$\uparrow$ Deceased.

${ }^{1}$ Present address: Maria de Lourdes Ribeiro de Souza da Cunha. Instituto de Biociências de Botucatu, UNESP, Departamento de Microbiologia e Imunologia. Rua Professor Doutor Antonio Celso Wagner Zanin, s/n - CEP 18618-689. Botucatu, São Paulo - Brasil.
}

the icaD gene is co-transcribed with the icaA gene. Protein IcaC permits the production of complete oligomers and IcaB plays a role in the deacetylation of the exported carbohydrate, facilitating intercellular adhesion. In ica-negative strains, biofilm production is mediated by accumulation-associated protein (Aap) or by biofilm-associated protein (Bap) and the Bap homologue protein (Bhp) found in S. epidermidis (Ziebuhr et al., 2006). These molecules are involved in intercellular aggregation, in which Aap is associated with the secretion of proteinbased biofilms, while Bap and Bhp are involved in the detachment of biofilm cells (Rohde et al., 2005; Tormo et al., 2007). However, the similarities and differences in the biofilm produced by $S$. epidermidis and S. haemolyticus remain unclear.

Therefore, the aim of this study was to characterize blood culture isolates of $S$. epidermidis and S. haemolyticus regarding the presence of the biofilm genes icaA, icaD and $b h p$ and biofilm formation evaluated by two phenotypic methods.

\section{Material and methods}

\subsection{Isolates}

The isolates were obtained from blood cultures of inpatients admitted to the University Hospital of the Botucatu Medical School (Hospital das Clínicas, Faculdade de Medicina de Botucatu - HC-FMB), Paulista 
Table 1

Primer sequence, TaqMan® probe, and amplicon size.

\begin{tabular}{|c|c|c|c|c|}
\hline Name & Product & Sequence & Reference & Amplicon size (bp) \\
\hline$i c a A-1$ & IcaA & 5'-AAAGATGTAGGTTATTGGGATACTGACA-3' & 10 & - \\
\hline$i c a A-2$ & & 5'-CATAGAGCACGTGGTTCGTACTTAA-3' & & \\
\hline icaA probe TaqMan ${ }^{\circledR}$ & & FAM-5'-TGCTGTTTCATGGAAACTCCATCTTTTTGATTA- 3'-TAMRA & & \\
\hline$i c a D-1$ & IcaD & 5'-ATCGTTGTGATGATTGTTTA-3' & 11 & - \\
\hline$i c a D-2$ & & 5'- GATATGTCACGACCTTTCTT-3' & & \\
\hline bhp-1 & Bhp & 5'-ATGAAAAATAAACAAGGATTTC-3' & 12 & 1278 \\
\hline bhp-2 & & 5'-GCCTAAGCTAGATAATGTTTG-3' & & \\
\hline
\end{tabular}

State University (Universidade Estadual Paulista - UNESP), Botucatu Campus, between 2000 and 2011. Only one isolate per patient was included in the study. The isolates were isolated as described by Koneman et al. (1997).

\subsection{Species identification}

The genus Staphylococcus was identified as described by Koneman et al. (1997). Staphylococcus epidermidis and S. haemolyticus were identified by the simplified method proposed by Cunha et al. (2004). Species identification was genetically confirmed by PCR amplification of the 16S-23S internal transcribed spacer (ITS) region as described by Couto et al. (2001) after DNA extraction with the Illustra kit (GE Healthcare, Little Chalfont, UK). The following international reference strains were used as controls: S. epidermidis (ATCC 12228), S. epidermidis (ATCC 35983), and S. haemolyticus (ATCC 29970).

\subsection{Detection of the biofilm-associated genes icaA and icaD}

The protocol proposed by Vandecasteele et al (Vandecasteele et al., 2003) was used for detection of the icaA gene by real-time PCR in the StepOnePlus ${ }^{\circledR}$ (Life) system. The reaction mixture contained $2 \mu \mathrm{L}$ nucleic acids, $12.5 \mu \mathrm{L}$ of $2 \times$ TaqMan ${ }^{\circledR}$ Fast Advanced Master Mix (PE Applied Biosystems), $900 \mathrm{nmol} / \mathrm{L}$ of each primer, and $200 \mathrm{nmol} / \mathrm{L}$ of the probe in a final volume of $25 \mu \mathrm{L}$. Parameters included initial holding at $50^{\circ} \mathrm{C}$ for $2 \mathrm{~min}$, denaturation for $20 \mathrm{~s}$ at $95^{\circ} \mathrm{C}, 40$ cycles of $1 \mathrm{~s}$ at $95^{\circ} \mathrm{C}$, and $20 \mathrm{~s}$ at $60{ }^{\circ} \mathrm{C}$. For icaD, the primers described by Tan et al., (2012) were used in a reaction mixture containing $4 \mu \mathrm{L}$ DNA, $0.3 \mu \mathrm{M}$ of each primer, and $10 \mu \mathrm{L}$ of $2 \times$ Fast Syber Green ${ }^{\circledR}$ Master Mix in a final volume of $20 \mu \mathrm{L}$. After initial denaturation at $95{ }^{\circ} \mathrm{C}$ for $20 \mathrm{~s}, 40$ cycles at $95{ }^{\circ} \mathrm{C}$ for $3 \mathrm{~s}$ and annealing and extension at $60^{\circ} \mathrm{C}$ for $30 \mathrm{~s}$ were performed. After amplification, the dissociation curve was analyzed to verify the specificity of the reactions (icaD: $\mathrm{Tm}=69 \pm 2{ }^{\circ} \mathrm{C}$ ). The primer sequences and TaqMan ${ }^{\circledR}$ probe are shown in Table 1.

\subsection{Detection of the biofilm-associated gene bhp}

The reactions for detection of the bhp gene were performed according to Qin et al (Qin et al., 2007). The primers are described in Table 1.

\subsection{Investigation of biofilm production by adherence to borosilicate} test tubes

Biofilm production was evaluated using the tube adherence test proposed by Christensen et al (Christensen et al., 1982). Blood agar colonies were inoculated into tryptic soy broth (TSB) containing $2 \%$ glucose. Trypan blue (Sigma) was used for staining. The presence of a layer of stained material adhered to the inner wall of the tubes was defined as a positive result. The exclusive presence of a stained ring at the liquidair interface was not classified as positive.

2.6. Investigation of biofilm production by adherence to polystyrene plates (Christensen et al., 1985)

Biofilm production was evaluated on polystyrene plates as proposed by Christensen et al (Christensen et al., 1985) and modified by Oliveira and Cunha (Oliveira and Cunha, 2010), using optical density readings of the adherent material produced by bacteria. Three to five colonies of each isolate were cultured for $22 \mathrm{~h}$ in TSB plus $2 \%$ glucose, adjusted to a 0.5 McFarland standard (corresponding to $1.5 \times 10^{8} \mathrm{CFU} / \mathrm{mL}$ ), and diluted $1: 1$ in TSB-2\% glucose. This suspension was transferred to polystyrene plates and incubated for $24 \mathrm{~h}$ at $37^{\circ} \mathrm{C}$. The plates were washed with phosphate-buffered saline, dried, and stained with crystal violet. The cutoff was calculated according to the formula of Christensen et al. (Qin et al., 2007) using a 540-nm filter. The isolates were classified into 3 categories: non-adherent, optical density $\leq 0.111$; weakly adherent, optical density $>0.111$ or $\leq 0.222$; strongly adherent, optical density $>0.222$.

\subsection{Statistical analysis}

The chi-square test was used to verify the association between variables, adopting a level of significance of $<0.05$. kappa statistic was used to evaluate agreement between methods.

\section{Results}

A total of 169 isolates were analyzed, including 85 S. epidermidis and 84 S. haemolyticus. Table 2 shows the results of biofilm gene detection (ica and bhp) and biofilm formation evaluated by the adherence tests.

Table 2

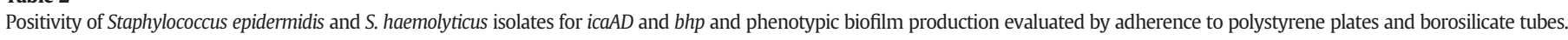

\begin{tabular}{|c|c|c|c|c|c|c|c|c|c|c|c|c|c|c|c|c|c|c|}
\hline \multirow{4}{*}{ Isolates (n) } & \multicolumn{8}{|c|}{ Biofilm genes } & \multicolumn{10}{|c|}{ Biofilm production } \\
\hline & \multicolumn{6}{|c|}{ Polysaccharide genes } & \multirow{2}{*}{\multicolumn{2}{|c|}{$\frac{\text { Protein gene }}{b h p}$}} & \multicolumn{6}{|c|}{ Plate test } & \multicolumn{4}{|c|}{ Tube test } \\
\hline & \multicolumn{2}{|c|}{$i c a A^{*}$} & \multicolumn{2}{|c|}{$i c a D^{* *}$} & \multicolumn{2}{|c|}{$i c a A D$} & & & \multicolumn{2}{|l|}{ SA } & \multicolumn{2}{|c|}{ WA } & \multicolumn{2}{|l|}{ NA } & \multicolumn{2}{|c|}{ Positive } & \multicolumn{2}{|c|}{ Negative } \\
\hline & $\mathrm{n}$ & $\%$ & $\mathrm{n}$ & $\%$ & $\mathrm{n}$ & $\%$ & $\mathrm{n}$ & $\%$ & $\mathrm{n}$ & $\%$ & $\mathrm{n}$ & $\%$ & $\mathrm{n}$ & $\%$ & $\mathrm{n}$ & $\%$ & $\mathrm{n}$ & $\%$ \\
\hline S. epidermidis (85) & 24 & 28.2 & 0 & 0 & 43 & 50.6 & 13 & 15.3 & 12 & 14.1 & 18 & 21.2 & 55 & 64.7 & 30 & 35.3 & 55 & 64.7 \\
\hline S. haemolyticus (84) & 2 & 2.4 & 35 & 45.7 & 36 & 42.9 & 0 & 0 & 1 & 1.2 & 16 & 19 & 67 & 79.8 & 18 & 21.5 & 66 & 78.6 \\
\hline Total (169) & 26 & 13.8 & 35 & 20.7 & 79 & 46.7 & 13 & 7.7 & 13 & 7.7 & 34 & 20.1 & 122 & 72.2 & 48 & 28.4 & 121 & 71.6 \\
\hline
\end{tabular}

$\mathrm{SA}=$ strongly adherent; $\mathrm{WA}=$ weakly adherent; $\mathrm{NA}=$ non-adherent.

$i c a A^{*}=i c a A$ alone.

$i c a D^{* *}=i c a D$ alone. 
Table 3

ica and bhp gene profile of Staphylococcus epidermidis and S. haemolyticus isolates that produced a strongly and weakly adherent biofilm.

\begin{tabular}{|c|c|c|c|c|c|c|c|c|}
\hline & \multicolumn{4}{|l|}{ SA } & \multicolumn{4}{|l|}{ WA } \\
\hline & $i c a A D$ & $i c a A^{*}$ & $i c a D^{* *}$ & bhp & $i c a A D$ & $i c a A^{*}$ & $i c a D^{* *}$ & bhp \\
\hline S. epidermidis & 10 & 1 & 0 & 1 & 13 & 3 & 0 & 2 \\
\hline S. haemolyticus & 1 & 0 & 0 & 0 & 9 & 0 & 6 & 0 \\
\hline Total & 11 & 1 & 0 & 1 & 22 & 3 & 6 & 2 \\
\hline
\end{tabular}

$\mathrm{SA}=$ strongly adherent; $\mathrm{WA}=$ weakly adherent.

$i c a A^{*}=i c a A$ alone.

$i c a D^{* *}=i c a D$ alone

A strongly adherent biofilm was detected in only one S. haemolyticus isolate, while $12(14.1 \%)$ S. epidermidis isolates produced a strongly adherent biofilm in the plate test. In the borosilicate tube test, the prevalence of biofilm formation was $35.3 \%$ in S. epidermidis and $21.5 \%$ in S. haemolyticus.

Most S. epidermidis isolates carried the icaA gene (78.8\%), while $84.5 \%$ of $S$. haemolyticus carried icaD. The exclusive presence of icaA was observed in $28.2 \%$ and $2.4 \%$ of the S. epidermidis and S. haemolyticus isolates, respectively. These frequencies were $0 \%$ and $45.7 \%$ for $i c a D$.

It was observed that $94.9 \%$ of the $S$. haemolyticus isolates carrying icaA also carried icaD, and icaA was present in all icaD-positive S. epidermidis isolates. Eleven of the 84 S. haemolyticus isolates and 18 of the $85 \mathrm{~S}$. epidermidis isolates were ica negative, corresponding to 29 (15.5\%) isolates that were negative for these genes. The bhp gene was detected only in S. epidermidis isolates (15.3\%).

Only 4 isolates ( $1 \mathrm{~S}$. haemolyticus and $3 \mathrm{~S}$. epidermidis) were biofilm producers, but icaA or icaD negative. Forty-six isolates (26 S. haemolyticus and 20 S. epidermidis) were positive for $i c a A D$ and biofilm negative. Among all isolates classified as strongly adherent ( $n=13,7.7 \%)$, only one $(0.6 \%)$ did not carry icaA or icaD and one ( $0.6 \%)$ carried only icaA but was bhp positive. Table 3 shows the gene profile of isolates that were strongly and weakly adherent in the plate test.

The concomitant presence of $i c a A$ and $i c a D$ was significantly associated with adherence. in the polystyrene plate test $(P=0.0004)$ and borosilicate tube test $(P \leq 0.0001)$. This association was also observed for S. epidermidis ( $P=0.0015$ and $P=0.0004$, respectively) when the two species were analyzed separately, but not for $S$. haemolyticus.

kappa agreement between the phenotypic methods was 0.9854 for all isolates, 1.0 for S. epidermidis, and 0.9639 for S. haemolyticus.

\section{Discussion}

The pathogenesis of CoNS infections in medical devices is mainly due to the ability of these microorganisms to produce a biofilm. In the present study, biofilm formation was found in $35.3 \%$ of the S. epidermidis isolates. Higher (Oliveira and Cunha, 2010; Ninin et al., 2006) and lower (de Silva et al., 2002) rates of biofilm formation have been reported for that species depending on the origin and localization of the isolates.

The bhp gene was detected in 13 (15.3\%) of the S. epidermidis isolates. Bowden et al., (2005) detected this gene in only $9 \%, 0 \%$, and $13 \%$ of bacteremia, blood culture contaminants, and skin isolates, respectively. Studies have shown that Bhp is important for the formation of a strongly adherent biofilm (Bowden et al., 2005). However, in the present study, only three of the 13 isolates carrying bhp were able to produce a detectable biofilm. Other molecules may play a more important role in strongly adherent biofilms of blood culture isolates. Further studies are needed to determine the function of Bhp in the establishment of a mature and functional biofilm.

The frequency of $S$. haemolyticus biofilm producers was $21.5 \%$. In contrast, Fredheim et al. (2009), using the same phenotypic method, detected $74 \%$ of biofilm producers. According to these authors, S. haemolyticus mainly produces a PIA-independent biofilm. Our results confirm this hypothesis since the ica genes were significantly associated with biofilm formation in S. epidermidis, but not in S. haemolyticus. As in
S. haemolyticus, PIA-independent biofilms have also been described in S. epidermidis, S. aureus, and S. lugdunensis (Qin et al., 2007; Fitzpatrick et al., 2005; Frank and Patel, 2007). The bhp gene was also not detected in any of the S. haemolyticus isolates, suggesting that this gene does not contribute relevantly to the protein components of S. haemolyticus biofilms, different from S. epidermidis.

It is assumed that staphylococci isolated from infected sites must be able to form a biofilm, produce PIA, and contain the ica operon. However, Fitzpatrick et al. (2005) suggested that the presence of the ica locus alone is not sufficient for biofilm formation. We found $62.1 \%$ of isolates carrying icaA, including $78.8 \%$ of S. epidermidis and $45.2 \%$ of S. haemolyticus isolates, while the icaD gene was detected in $67.5 \%$ of CoNS, including $50.6 \%$ of S. epidermidis and $84.5 \%$ of S. haemolyticus isolates. In contrast, other authors described only four of $72 \mathrm{~S}$. haemolyticus isolates carrying icaD (Fredheim et al., 2009). Both icaA and icaD were detected in $50.6 \%$ of $S$. epidermidis and $42.9 \%$ of $S$. haemolyticus isolates, respectively. Similar results have been reported by Oliveira and Cunha (Oliveira and Cunha, 2010) who observed $40 \%$ of icaAD positivity. Other studies found icaD in $77 \%$ of CoNS and icaA in $27.8 \%$, most of them S. epidermidis (Hernández et al., 2010).

Although exhibiting weak $N$-acetylglucosaminyl transferase activity, the IcaA protein plays an important role in the synthesis of PIA since IcaD and the other components of the Ica system do not have exclusive transferase activity (Gerke et al., 1998). We may suggest the presence of icaA in most of the S. epidermidis isolates, in spite of S. haemolyticus, to be associated with the larger number of biofilm-producing S. epidermidis strains, although this association was not statistically significant. The role of icaD in S. haemolyticus isolates should be investigated since this gene apparently showed no correlation with the S. haemolyticus biofilm, although it was detected at a high frequency in that species.

Eleven of the 13 isolates classified as strongly adherent carried icaAD. De Silva et al (de Silva et al., 2002) described an association between the ica operon and quantitative biofilm formation, while other authors could not find such association in clinical isolates of S. epidermidis (Ninin et al., 2006; de Silva et al., 2002). In the present study, the concomitant presence of $i c a A D$ was significantly associated with biofilm production, highlighting the important role of these genes in biofilm formation. Furthermore, genes involved in biofilm formation have been suggested as potential markers of clinically relevant isolates. It is believed that isolates carrying the ica genes possess a competitive advantage in medical device colonization, especially in the case of long-term catheters (Ninin et al., 2006).

In our study, four isolates did not produce a biofilm, regardless of the concomitant presence of the $i c a A$ and $i c a D$ genes. The expression of ica mRNA has been demonstrated in non-biofilm-producing S. epidermidis and in isolates that do not produce a biofilm or produce an undetectable biofilm under experimental conditions (Dobinsky et al., 2003). Apparently, PIA production is subjected to the on/off activity of its coding genes that may be involved in a phase variation in S. epidermidis, conditions that facilitate bacterial survival and growth under changing environmental conditions in vivo (Ziebuhr et al., 1999). Moreover, evidence supports the hypothesis of dissemination of new clones referred to as biofilm negative, but positive for both icaA and icaD (Arciola et al., 2001).

The kappa agreement between the polystyrene plate method and the borosilicate tube test was 0.9854 , similar to the value reported by Oliveira and Cunha (Oliveira and Cunha, 2010).The tube test has shown low sensitivity in the detection of biofilm formation in other studies (Hassan et al., 2011). However, its routine use is justified by its high efficacy in detecting biofilms, its easy and practical application, and good results obtained in this and in other studies (Cunha et al., 2006). The addition of glucose to the TSB medium is indicated since it increases the sensitivity of detection (Kim, 2001).

Differences in biofilm formation related to the presence of associated genes and even between phenotypic methods may be due to the influence of different culture media, $\mathrm{pH}$, temperature, and osmotic pressure. 
Possible differences between in vitro and in vivo biofilm formation may be related to factors such as stress and molecules released by the host immune system.

\section{Conclusions}

The biofilm of $S$. epidermidis seems to be associated with the presence of the icaA gene and, to a lesser extent, with bhp. The ica and bhp genes do not seem to play an important role in biofilm production by S. haemolyticus, although the icaD gene was found at a high frequency in that species. Biofilm production is an indicator of the potential persistence of clinical strains of S. epidermidis and S. haemolyticus.

\section{Conflicts of interest}

None to declare.

\section{Acknowledgements}

This work was supported by the state funding agency Fundação de Amparo à Pesquisa do Estado de São Paulo (FAPESP; Grant 2011/15396-1).

\section{References}

Arciola CR, Collamati S, Donati E, Montanaro L. A rapid PCR method for the detection of slime-producing strains of Staphylococcus epidermidis and Staphylococcus aureus in periprosthesis infections. Diagn Mol Pathol 2001;10:130-7.

Bowden MG, Chen W, Singvall J, Xu Y, Peacock SJ, Valtulina V, et al. Identification and preliminary characterization of cell-wall-anchored proteins of Staphylococcus epidermidis. Microbiology 2005;151:1453-64.

Christensen GD, Simpson WA, Bisno AL, Beachey EH. Adherence of slime producing strains of Staphylococcus epidermidis to smooth surfaces. Infect Immun 1982;37:318-26.

Christensen GD, Simpson WA, Yonger JJ, Baddor LM, Barrett FF, Melton DM, Beachey EH. Adherence of coagulase-negative staphylococci to plastic tissue culture plates: a quantitative model for the adherence of staphylococci to medical devices. J Clin Microbiol 1985;22:996-1006.

Couto I, Pereira S, Miragaia M, Sanches IS, Lencastre H. Identification of clinical staphylococcal isolates from humans by Internal Transcribed Spacer PCR. J Clin Microbiol 2001;39: 3099-103.

Cunha MLRS, Sinzato YK, Silveira LVA. Comparison of methods for identification of coagulase-negative staphylococci. Mem Inst Oswaldo Cruz 2004;99:855-60.

Cunha MLRS, Rugolo LMSS, Lopes CAM. Study of virulence factors in coagulase-negative staphylococci isolated from newborns. Mem Inst Oswaldo Cruz 2006;101:661-8.

de Silva GD, Kantzanou M, Justice A, Massey RC, Wilkinson AR, Day NPt. al. The ica operon and biofilm production in coagulase-negative staphylococci associated with carriage and disease in a neonatal intensive care unit. J Clin Microbiol 2002;40(2):382-8.

Dobinsky S, Kiel K, Rohde H, Bartscht K, Knobloch JK, Horstkotte MA, et al. Glucose-related dissociation between icaADBC transcription and biofilm expression by Staphylococcus epidermidis: evidence for an additional factor required for polysaccharide intercellular adhesin synthesis. J Bacteriol 2003;185(9):2879-86.
Fitzpatrick F, Humphreys H, O'Gara JP. Evidence foricaADBC-independent biofilm development mechanism in methicillin-resistant Staphylococcus aureus clinical isolates. J Clin Microbiol 2005;43:1973-6.

Frank KL, Patel R. Poly- $N$-acetylglucosamine is not a major component of the extracellular matrix in biofilms formed by icaADBC-positive Staphylococcus lugdunensis isolates. Infect Immun 2007;75:4728-42.

Fredheim EGA, Klingenberg C, Rohde H, Frankenberger S, Gaustad P, Flægstad T, et al. Biofilm formation byStaphylococcus haemolyticus. J Clin Microbiol 2009;47(4): 1172-80.

Gerke C, Kraft A, Sussmuth R, Schweitzer O, Gotz F. Characterization of the $\mathrm{N}$-acetylglucosaminyltransferase activity involved in the biosynthesis of the Staphylococcus epidermidis polysaccharide intercellular adhesin. J Biol Chem 1998;273: 18586-93.

Hassan A, Usman J, Kaleem F, Omair M, Khalid A, Iqbal M. Evaluation of different detection methods of biofilm formation in the clinical isolates. Braz J Infect Dis 2011;15(4): 305-11.

Hernández BD, Santos FS, Miranda BL, Bejarano LP, Novales GM. Production oficaADBCencoded polysaccharide intercellular adhesin and therapeutic failure in pediatric patients with staphylococcal device-related infections. BMC Infect Dis 2010;10:68. http://dx.doi.org/10.1186/1471-2334-10-68.

Huebner J, Goldmann DA. Coagulase-negative staphylococci: role as pathogens. Annu Rev Med 1999;50:223-36.

Kim L. Riddle of biofilm resistance. Antimic Agents Chemother 2001;45(4):999-1007.

Koneman EW, Allen SD, Janda WM, Schreckenberger PC, Winn Jr WC. Color atlas and textbook of diagnostic microbiology. 5th ed. Philadelphia: Lippincott; 1997.

Mack D, Davies AP, Harris LG, Rohde H, Horstkotte MA, Knobloch JK. Microbial interactions in Staphylococcus epidermidis biofilms. Anal Bioanal Chem 2007;387: 399-408.

Ninin E, Caroff N, Espaze E, Maraillac J, Lepelletier D, Milpied N, et al. Assessment of ica operon carriage and biofilm production in Staphylococcus epidermidis isolates causing bacteraemia in bone marrow transplant recipients. Clin Microbiol Infect 2006;12(5): 446-52.

Oliveira A Cunha MLRS. Comparison of methods for the detection of biofilm production in coagulase-negative staphylococci. BMC Res Notes 2010;3:260. [http://www. biomedcentral.com/1756-0500/3/260].

Qin Z, Yang X, Yang L, Jiang J, Ou Y, Molin S, Qu D. Formation and properties of in vitro biofilms of ica-negative Staphylococcus epidermidis clinical isolates. J Med Microbiol 2007;56:83-93.

Rohde H, Burdelski C, Bartscht K, Hussain M, Buck F, Horstkotte MA, et al. Induction of Staphylococcus epidermidis biofilm formation via proteolytic processing of the accumulation-associated protein by staphylococcal and host proteases. Mol Microbiol 2005;55(6):1883-95.

Tan H, Peng Z, Li Q, Xu X, Guo S, Tang T. The use of quaternised chitosan-loaded PMMA to inhibit biofilm formation and downregulate the virulence-associated gene expression of antibiotic-resistant Staphylococcus. Biomaterials 2012;33:365-77.

Tormo MA, Ubeda C, Martí M, Maiques E, Cucarella C, Valle J, et al. Phase-variable expression of the biofilm-associated protein (Bap) in Staphylococcus aureus. Microbiology 2007; 153(Pt 6):1702-10.

Vandecasteele SJ, Peetermans WE, Merckx R, Van Eldere J. Expression of biofilmassociated genes and in vivo foreign body infections. J Infect Dis 2003;188:730-7.

Vuong C, Otto M. Staphylococcus epidermidis infections. Microbes Infect 2002;4:481-9.

Ziebuhr W, Krimmer V, Rachid S, Lössner I, Götz F, Hacker J. A novel mechanism of phase variation of virulence in Staphylococcus epidermidis: evidence for control of the polysaccharide intercellular adhesin synthesis by alternating insertion and excision of the insertion sequence element IS256. Mol Microbiol 1999;32(2):345-56.

Ziebuhr W, Hennig S, Eckart M, Kranzler H, Batzilla C, Kozitskaya S. Nosocomial infections by Staphylococcus epidermidis: how a commensal bacterium turns into a pathogen. Int J Antimicrob Agents 2006;28:S14-20. 